


\section{Socio-economic aspects of a change in coccidiosis control programme in broiler diets in the Netherlands}

P. van Horne ${ }^{1}$, J. van Harn²

1 Wageningen Economic Research

2 Wageningen Livestock Research

This research has been commissioned by LTO Nederland (Dutch Federation of Agriculture and Horticulture) and was funded by Elanco Benelux \& Nordic.

Wageningen Economic Research

Wageningen, January 2019

REPORT

2019-004

ISBN 978-94-6343-585-7 
P. van Horne, J. van Harn, 2019. Socio-economic aspects of a change in coccidiosis control programme in broiler diets in the Netherlands. Wageningen, Wageningen Economic Research, Report 2019-004. 28 pp.; 7 fig.; 8 tab.; 15 ref.

This report can be downloaded for free at https://doi.org/10.18174/469970 or at www.wur.eu/economic-research (under Wageningen Economic Research publications).

(C) 2019 Wageningen Economic Research

P.O. Box 29703, 2502 LS The Hague, The Netherlands, T +31 (0)70 3358330 ,

E communications.ssg@wur.nl, http://www.wur.eu/economic-research. Wageningen Economic Research is part of Wageningen University \& Research.

\section{(cc) BY-NC}

For its reports, Wageningen Economic Research utilises a Creative Commons Attributions 3.0 Netherlands license.

(C) Wageningen Economic Research, part of Stichting Wageningen Research, 2019

The user may reproduce, distribute and share this work and make derivative works from it. Material by third parties which is used in the work and which are subject to intellectual property rights may not be used without prior permission from the relevant third party. The user must attribute the work by stating the name indicated by the author or licensor but may not do this in such a way as to create the impression that the author/licensor endorses the use of the work or the work of the user. The user may not use the work for commercial purposes.

Wageningen Economic Research accepts no liability for any damage resulting from the use of the results of this study or the application of the advice contained in it.

Wageningen Economic Research is ISO 9001:2008 certified.

Wageningen Economic Research Report 2019-004 | Project code 2282100282

Cover photo: Shutterstock 


\section{Contents}

Preface $\quad 5$

$\begin{array}{ll}\text { Summary } & 6\end{array}$

1

\begin{tabular}{l|l} 
Introduction & 8
\end{tabular}

1.1 Problem statement $\quad 8$

1.2 Objectives $\quad 8$

$\begin{array}{lll}1.3 & \text { Structure of the research } & 8\end{array}$

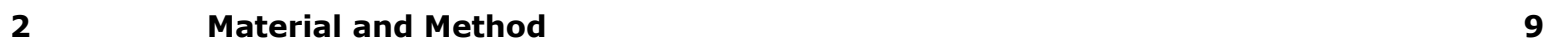

$2.1 \quad$ Norway data $\quad 9$

2.2 Comparison of Norwegian results with the Netherlands and Denmark $\quad 11$

$\begin{array}{ll}2.3 & \text { Netherlands compared to Norway } \\ 2.4 & 13\end{array}$

2.4 Additional costs 14

2.5 Scenarios $\quad 15$

3

$\begin{array}{ll}\text { Results } & 17\end{array}$

$\begin{array}{lll}3.1 & \text { Economic results } & 17\end{array}$

$\begin{array}{ll}3.2 & \text { Environmental impact } \\ 3.3 & \text { Other aspects }\end{array}$

$\begin{array}{lll}3.3 & \text { Other aspects } & 20\end{array}$

4 Conclusions $\quad 23$

$\begin{array}{ll}\text { References and websites } & \mathbf{2 4}\end{array}$

Appendix 1 Nortura slaughter control data: feed conversion 2014 and 2017

Appendix 2 Nortura slaughter control data: mortality percentage data 2014 and 2017 



\section{Preface}

Coccidiosis is a common disease in modern broiler production. Anticoccidials are widely used as a feed additive to prevent coccidiosis causing mortality and poor production results. In Norway farmers have changed their anticoccidial programme from the use of ionophore anticoccidials to vaccination, after negative media attention on these products. A Norwegian scientist went to the media stating that Narasin (until then the most used anticoccidial in Norway) leads to emerging E.coli ESBL (Extended Spectrum Betalactamse). As a consequence, retail in Norway asked broiler farms for a change in the coccidiosis control programme and farmers stopped with the routine use of anticoccidials. On a study tour to Norway some Dutch farmers learned about this change in Norway.

Dutch poultry farmers, organised in the farmers' organisation LTO, are concerned about a similar change in the coccidiosis control programme in the Netherlands. The possible consequences in the Netherlands could be much larger compared to Norway, as there are more and larger farms in a smaller area with, in general, a higher infection pressure. LTO asked Wageningen University \& Research to perform a scenario study in which the consequences of a possible stop of the routine use of anticoccidials in broiler diets in the Netherlands will be evaluated.

This report is a result of a cooperation between two institutes of WUR. Wageningen Livestock Research researcher Jan van Harn provided the necessary knowledge on poultry nutrition and broiler husbandry. This knowledge was supplementary to the expertise of Wageningen Economic Research with a focus on economics and scenario studies.

The authors would like to thank LTO and Elanco for commissioning the project. The project was funded by Elanco Benelux \& Nordic. The authors also would like to thank all persons and organisations in Norway, Denmark and the Netherlands who provided information and data.

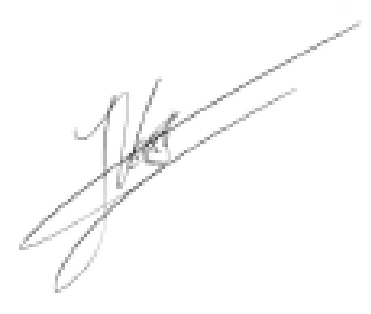

Prof.dr.ir. J.G.A.J. (Jack) van der Vorst

General Director Social Sciences Group (SSG)

Wageningen University \& Research 


\section{Summary}

In the broiler sector, farmers use feed with anticoccidials to prevent cocccidiosis. Coccidiosis is a common disease in modern broiler production and an outbreak is very costly. A reduced coccidiosis control leads to compromised intestinal integrity, which allows proliferation of Clostridia perfringens. This can cause Necrotic Enteritis and will lead to a poorer performance of the birds. In Norway the routine use of ionophore anticoccidials was stopped after media attention on suspected negative aspects. As a result one large retailer has prohibited the preventive use of in-feed anticoccidials and farmers who supply their broilers to this retailer prevent routine coccidiosis by vaccinating the broilers. According to Norwegian poultry specialists, this voluntary stop of the routine use resulted in deteriorated production results. Dutch poultry farmers, organised in the farmers' organisation LTO, are concerned about a stop of the routine use of anticoccidials in the Netherlands. The possible consequences in the Netherlands could be much larger compared to Norway. LTO asked Wageningen University \& Research to perform a scenario study to evaluate the consequences of a possible change in the Netherlands.

In the first part of this study the data of Norwegian broiler farms were collected and analysed. In the second part, a socio-economic analysis of a stop on the routine use of anticoccidials was conducted. The main results and conclusions are:

\section{Higher feed conversion and mortality percentage}

- The results of broilers farms of a large Norwegian slaughterhouse show that after stopping the routine use of anticoccidials in the feed the production results deteriorated. Comparing the situation of 2014 (before) with 2017 (after) showed a higher mortality and a poorer feed conversion in 2017.

- Normally broiler production results improve every year as a result of genetic improvements. To show the improvement between 2014 and 2017, the production results of the Netherlands and Denmark were compared to the data of Norway. Based on this comparison it was concluded that the impact of stopping the routine use on anticoccidials in the broiler feed in Norway led to a 0.04 higher feed conversion and a higher mortality percentage of 0.9

- In the Netherlands the structure of the broiler sector is different from Norway. There are more broilers farms in a small region, the average farm is much larger, the stocking density on the farm is higher and farmers produce broilers with a higher live weight. All these factors will have an impact on the production results after stopping the routine use of anticoccidials. The WUR researchers discussed the consequences with two poultry veterinarians and it was concluded that in the Netherlands a 0.06 higher feed conversion and a higher mortality percentage of 1 can be expected.

\section{Higher production costs and lower farm incomes in all scenarios}

- To show the economic consequences for the Dutch broilers farmers in a situation without in-feed anticoccidials, three scenarios were described. In all scenarios the additional costs of vaccination are 2.5 eurocent. In scenario NO, the feed conversion is 0.04 higher and the mortality percentage is 0.9 higher. In scenario NL1, the feed conversion is 0.06 higher and mortality is $1.0 \%$ higher. In Scenario $\mathrm{NL2F}$, the feed conversion is 0.04 higher, mortality is $0.5 \%$ higher combined with an additional change in feed composition (a higher feed price of 0.01 eurocent per $\mathrm{kg}$ ) and adding probiotics (0.01 eurocent per broiler).

- Total production costs are 82.4 eurocent per $\mathrm{kg}$ live weight in the reference situation. In scenario NO, the costs are $85.5(+3.8 \%)$, scenario NL1 $86.1(+4.5 \%)$ and scenario NL2F $87.4(+6.1 \%)$. The total farm income of a Dutch farm in the reference situation is 81,800 euro. In scenario NO, the income is reduced to 35,600 euro, in scenario NL1 to 25,700 euro and in scenario NL2F to 5,900 euro. Figure S. 1 shows the results of the scenarios.

Higher environmental impact and concerns on animal welfare

- A higher feed conversion also has an environmental impact. The extra production of crops, transport of feed ingredients, feed processing and transport gives direct emissions. With a higher feed 
conversion of 0.04 and 0.06 the total carbon foot print at farm level increased from $1.73 \mathrm{CO}_{2}$ equivalents in the reference situation to 1.77 and $1.79 \mathrm{CO}_{2}$ equivalents, respectively. This is an increase of 2.3 and $3.4 \%$.

- In Norway, in newspapers and other media, some experts expressed their concern about reduced animal welfare in a situation after stopping the routine use of anticoccidials.

- In the Netherlands farmers and veterinarians are concerned about the animal health and animal welfare of the birds. To prevent an increase in mortality birds will be more often treated with antibiotics.

\section{Less efficient supply chain}

- Stopping with the routine use of anticoccidials will result in a wider variation in results. This is especially valid for the mortality rate. This makes planning by the farmers and slaughterhouse more complicated and makes the production chain less efficient. In a situation without anticoccidials in the feed, more rejects and liver condemnation and a more frequent use of antibiotics can be expected.

- Stopping the routine use of anticoccidials in the Netherlands will lead to an increased use of antibiotics. First, an increased risk of clinical necrotic enteritis will lead to a higher mortality. To prevent an increase in mortality, birds will be treated with antibiotics. In the Netherlands farmers, veterinarians and the government don't want an increase in mortality. Veterinarians will choose to preserve animal health and animal welfare. Second, an increase in mortality could force farmers to reduce the stocking density, due to EU legislation, with a direct negative impact on farm income.

- In a situation with higher production costs and no higher revenue prices, some of the Dutch farmers will stop farming. This will have direct consequences for the chain partners such as hatcheries, feed mills and slaughterhouses. The broiler supply chain in the Netherlands currently employs 16,000 workers. In the new situation, some of these workers will be unemployed.

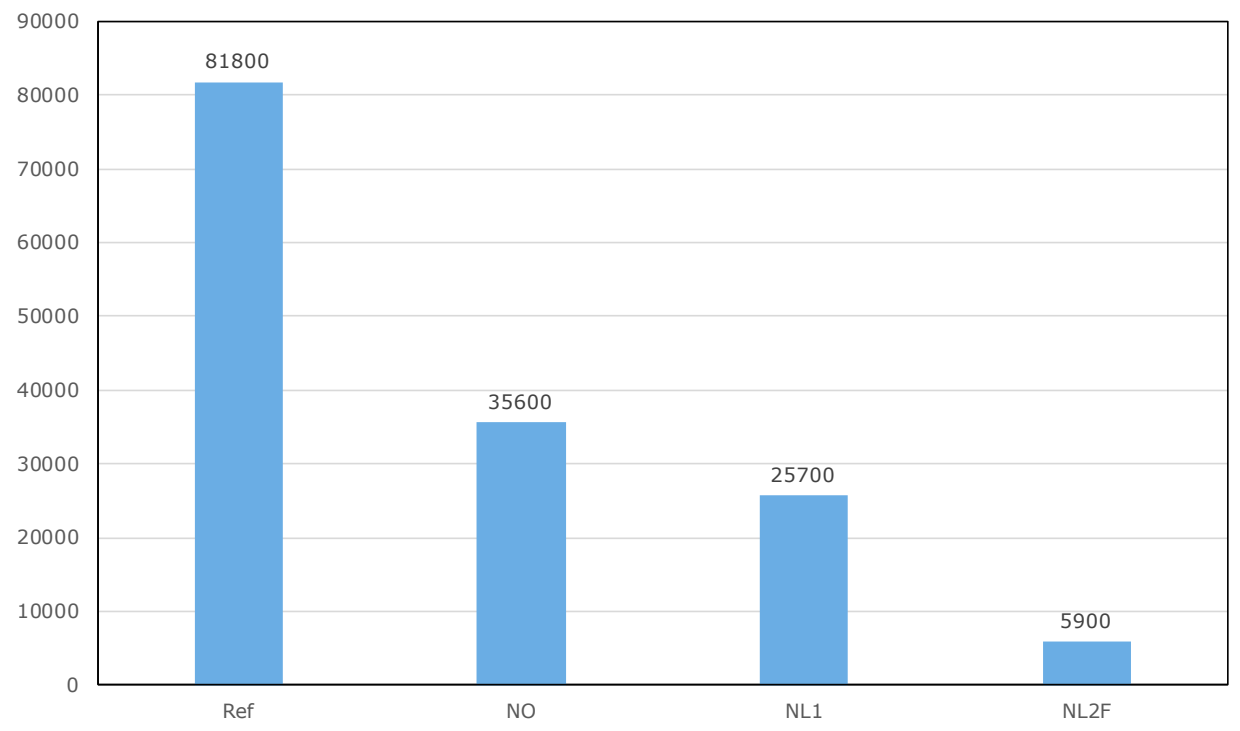

Figure S.1 Farm income (euros per farm per year) in the reference situation and three scenarios for Dutch broiler farms after a change in coccidiosis control 


\section{Introduction}

\subsection{Problem statement}

In the broiler sector, it is common to use anticoccidials in the feed to prevent coccidiosis. Coccidiosis is an intestinal disease that occurs when a microscopic parasitic organism (called a protozoa) invades the intestine of a chicken. Coccidiosis is a common disease in modern broiler production and an outbreak is very costly. Coccidiosis prevents the chicken from absorbing nutrients. A reduced coccidiosis control leads to compromised intestinal integrity which allows proliferation of Clostridia perfringens which then causes Necrotic Enteritis. Coccidiosis infection will cause mortality, decreased weight gain and deteriorated feed conversion. Coccidiosis has also a negative impact on the litter quality. Poor and wet litter quality can cause footpad lesions and a reduced animal welfare. Anticoccidials are a widely used as feed additive to prevent coccidiosis.

In Norway, retailers have prohibited the preventive use of in-feed anticoccidials. As a result farmers in Norway have changed their anticoccidial programme from the use of ionophore anticoccidials to vaccination. The reason for this was a Norwegian scientist who reported to the media at the end of 2014 that Narasin (until then the most-used anticoccidial in Norway) was causing E. coli and ESBL. The publication led to great consumer concern and a sharp decline in sales of poultry meat in the supermarket. As a consequence, retail asked for a change in the farmer's coccidiosis control programme. According to Norwegian poultry specialists, this stop on the use of in-feed anticoccidials resulted in a poorer feed conversion, higher mortality rate, an increased Narasin usage at clinical cases, and more downgrading at the slaughterhouse. In addition, other and more expensive raw materials for the feed are needed.

\subsection{Objectives}

The general objective of the project is to provide an overview of the socio-economic consequences of a stop of the routine use of anticoccidials in broiler diets in the Netherlands.

\subsection{Structure of the research}

The study will be divided into two parts. In the first part, the data on Norwegian broiler farms will be collected and analysed. The background of these data will be discussed with some specialists who have knowledge of the Norwegian situation. In the second part, a socio-economic analysis of a stop on the use of anticoccidials will be conducted. The study consists of the following tasks:

- Collect and analyse the Norway field data and discuss these data with some specialists

- Compare the Norwegian data with Dutch and Danish data

- Define several scenarios based on various expert assumptions

- Estimate the economic effect for the Dutch broiler farmer and the impact on the $\mathrm{CO}_{2}$-footprint.

This study is based on the Norway experience and all data will be analysed in detail. Also the data of the development on broiler farms in the Netherlands (period 2014-2017) will be collected and analysed. Subsequently, scenarios will be developed for the Dutch situation. One scenario is based on similar consequences as in Norway and two scenarios are based on more impact (on feed conversion, mortality and growth rate) for the Netherlands, as a result of the higher disease pressure, due to a higher poultry density, heavier broilers and larger farms. The scenarios are based on a stop in the Netherlands only and not an EU-wide stop on the use of anticoccidials. In the scenarios only the consequences on farm level will be described in detail. In this report, whenever we use the term 'anticoccidials' we refer to the ionophore anticoccidials. 


\section{Material and Method}

In this chapter we describe the data, the analysis of the data and we give an overview of the scenarios which describe the possible consequences in a situation without anticoccidials in the broiler feed on Dutch broiler farms. The Norwegian data are analysed step by step. In paragraph 2.1 we present the data as collected. In paragraph 2.2 these data are corrected for the general trend in improvement of feed conversion and mortality. This is necessary because the data from the Netherlands and Denmark show an improvement in production results between 2014 and 2017 . The next step, described in Section 2.3, is to give an estimate for the possible results for the Netherlands situation with larger farms and a much higher density of poultry farms compared to Norway. All this information is combined with the additional costs (Section 2.4) and results in some scenarios to estimate the possible situation for the Netherlands without anticoccidials in the broiler feed. The details of the scenarios are given in Section 2.5.

\section{$2.1 \quad$ Norway data}

We collected data of broiler farms from the cooperation Nortura. Nortura is Norway's largest food supplier and leading supplier of meat and eggs. Nortura is an agricultural cooperative and is owned by about 31,200 farmers throughout the country and is the leading slaughter company in Norway with three locations and a market share of $45 \%$ (Brantsaeter, director Norsk Fjorfelag). It is also the largest poultry meat producer and the products are sold under the brand name Prior. Nortura uses the standard fast-growing breeds, such as Ross and Cobb. Data on the other large slaughterhouse, Norsk Kylling, are not used because this company made the switch to slow growing breeds.

The company publishes monthly results of their broiler farms on the Internet (Nortura, 2018). Nortura collects detailed information of the farm results (slaughter weight, age of the birds, daily growth, feed conversion, mortality), economics (feed costs), slaughter quality (rejects) and animal welfare (footpad score).

Nortura presents the results of all flocks slaughtered per month. The number of flocks per months is 150 to 200 with a minimum of 119 flocks in December 2017. Appendix 1 and Appendix 2 give the results of 2014 and 2017 for the indicator feed conversion and mortality percentage. Besides the average per month, also the minimum, the maximum, the first quartile, the median and the third quartile are presented. In total 9 sheets give the results for 2014, 2015, 2016 and 2017.

Table 2.1 Results of Nortura broiler farms, 2014-2017

\begin{tabular}{|c|c|c|c|c|c|}
\hline \multirow[t]{2}{*}{ Indicator } & \multirow[t]{2}{*}{2014} & \multirow[t]{2}{*}{2015} & \multirow[t]{2}{*}{2016} & \multirow[t]{2}{*}{2017} & Difference \\
\hline & & & & & 2017-2014 \\
\hline number of flocks & 2600 & 2175 & 1858 & 1689 & \\
\hline slaughter weight (SW) (gram) & 1256 & 1249 & 1240 & 1382 & 126 \\
\hline age (days) & 31.5 & 31.2 & 31.5 & 33 & 1.5 \\
\hline feedconversion ( $\mathrm{kg}$ feed/kg SW) & 2.18 & 2.17 & 2.23 & 2.22 & 0.04 \\
\hline feed costs per kg SW (NOK) & 9.15 & 9.25 & 9.53 & 9.41 & 0.26 \\
\hline feed price, per kg (NOK) & 4.19 & 4.27 & 4.26 & 4.24 & 0.05 \\
\hline mortality, farm level (\%) & 2.64 & 2.94 & 3.63 & 3.18 & 0.54 \\
\hline
\end{tabular}


Table 2.1 gives the results of all the flocks per year. The footpad lesion score was done following the Swedish classification system (Berg, 1998), with a maximum score of 200. The weight of the broilers, the growth rate, feed conversion and feed cost per kg were all calculated per kg slaughter weight (sw). The slaughter weight was calculated from the live weight (Iw) by using a percentage of 66.7 $(\mathrm{sw}=0.667 * \mathrm{Iw})$. This is different from the approach in the Netherlands and Denmark where growth rate and feed conversion are calculated per $\mathrm{kg}$ of live weight.

Results feed conversion and mortality

The results in Table 2.1 show that from 2014/2015 towards 2016 and 2017 the feed conversion and the mortality increased. Feed conversion and mortality have a large impact on the production costs. For this reason we analysed in further detail the results for feed conversion and mortality. Figure 2.1 shows the development per month of the feed conversion.

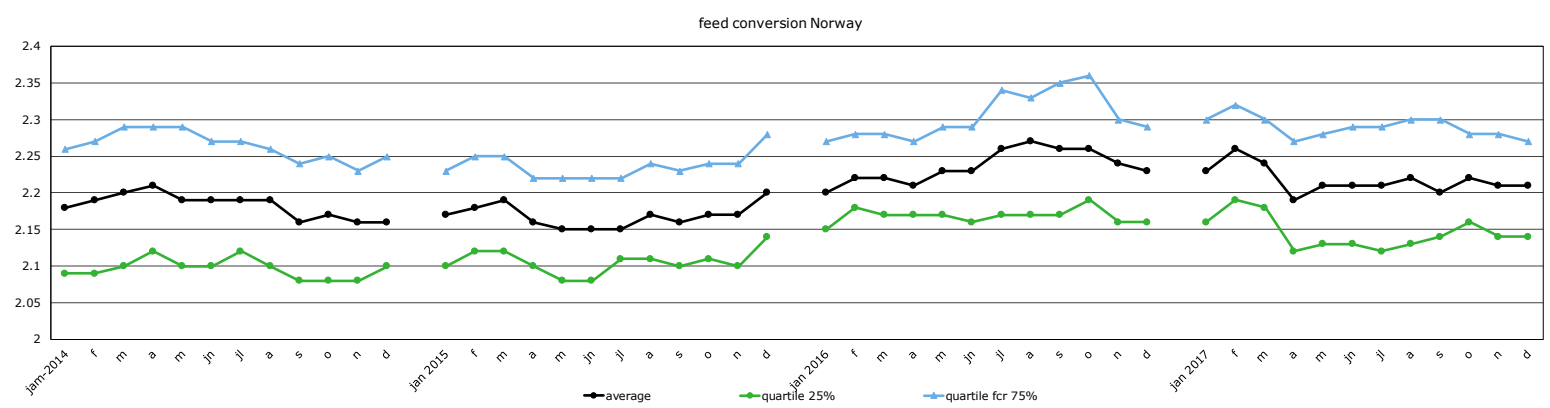

Figure 2.1 Feed conversion ( $k g$ feed/kg slaughter weight) per month in the period January 2014 to December 2017

Feed conversion is increasing from December 2015 and stays at a higher level until March 2017. From April 2017 the feed conversion is rather stable, but at a slightly higher level than in 2014 . The average feed conversion in 2017 was 2.22 compared to 2.18 for the year 2014 .

Figure 2.2 shows the development of the mortality per month in the period January 2014 till December 2017.

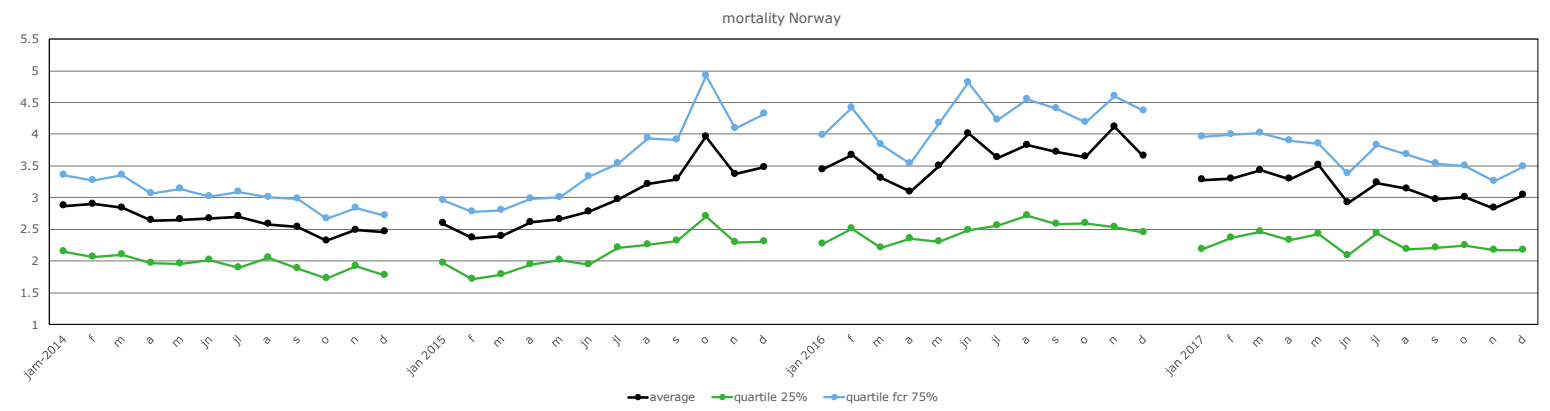

Figure 2.2 Mortality (\%) per month in the period January 2014 till December 2017

Mortality increases in the middle of 2015. From August 2015 until December 2017 the average mortality during all months (except for two months) is higher than $3 \%$. This is clearly higher than the average of 2014 , which was $2.64 \%$. In 2017 the mortality decreased to a more moderate level. In 2016 and 2017 the average mortality was 3.63 and $3.18 \%$. 


\section{Use of anticoccidials}

The results of the broiler farms in Norway are influenced by the voluntary stop of the routine use of anticoccidials in 2015. As a result of this farms now vaccinate against coccidiosis. The following periods can be distinguished:

- 2014: all farms use anticoccidials in the feed.

- 2015: early 2015 some farms (starting with the farms with the best production results) stopped with the routine use of anticoccidials in the feed and instead vaccinated the birds against coccidiosis. Other farms followed later in 2015. However, the main supplier of coccidiose vaccine, MSD Animal Health, had some problems in supplying the vaccine. In the July-October period 2015 the vaccine Paracox-5 (MSD Animal Health) was not available. In this period farmers didn't vaccinate or they used an alternative vaccine (e.g. Hipracox from Hipra).

- 2016: most farms have stopped with routine use of anticoccidials in the feed.

- 2017: all farms stopped with routine use of anticoccidials and vaccinate against coccidiosis.

\section{Conclusion}

A comparison of the average results of 2014 (before) with 2017 (after) gives a good overview of the difference in production results in Norway with and without anticoccidials in the broiler feed. Stopping with the routine use of anticoccidials in the feed resulted in deteriorated production results (e.g. higher mortality rate and a poorer feed conversion).

\subsection{Comparison of Norwegian results with the Netherlands and Denmark}

To compare the Norwegian results with the Dutch results, the Norwegian results were recalculated. The Norwegian data are recalculated towards results per $\mathrm{kg}$ live weight. The live weight is calculated from the slaughter weight with the $66.7 \%$ correction factor. Because the live weight is different between the years, the feed conversion and mortality are corrected towards a similar standard. The correction for feed conversion is 0.01 per 40 gram of live weight $(0.025$ per $100 \mathrm{~g})$. The correction for mortality is $0.06 \%$ per day (EU standard). Table 2.2 gives the results of recalculated Norwegian production results.

Table 2.2 Recalculated production results of Norway based on live weight

\begin{tabular}{|c|c|c|c|c|c|c|}
\hline & 2014 & 2015 & 2016 & 2017 & $\begin{array}{l}\text { difference } \\
2017-2014\end{array}$ & $\begin{array}{r}\text { difference, } \% \\
2017-2014\end{array}$ \\
\hline Live weight (gram) & 1883 & 1873 & 1859 & 2072 & 189 & 10.0 \\
\hline growth LW/day (gram) & 59.8 & 60.0 & 59.0 & 62.8 & 3.0 & 5.0 \\
\hline $\mathrm{kg}$ feed per bird & 2738 & 2710 & 2765 & 3068 & 330 & 12.1 \\
\hline feed conversion at $1.90 \mathrm{~kg}$ & 1.458 & 1.454 & 1.498 & 1.438 & -0.021 & -1.4 \\
\hline mortality, farm level (\%) & 2.64 & 2.94 & 3.63 & 3.18 & 0.54 & 20.5 \\
\hline mortality, farm level (\%) at 31.5 days & 2.64 & 2.96 & 3.63 & 3.09 & 0.45 & 17.0 \\
\hline
\end{tabular}

From Table 2.2 we can conclude that comparing 2017 (with routine use of anticoccidials) with 2014 (without routine use of anticoccidials) gives the following differences:

- Higher live weight (+189 gram or $10 \%)$

- Feed conversion is 0.027 point higher $(+1.8 \%)$

- Corrected feed conversion (at live weight of $1.9 \mathrm{~kg}$ ) is 0.021 lower $(-1.4 \%)$

- Mortality during the growing period is 0.54 higher ( $+20.5 \%)$

- Corrected mortality (at 31.5 days growing period) is 0.45 higher $(+17 \%)$

Normally broiler production results improve year by year as a result of genetic improvements. To show the improvement between 2014 and 2017 we give the production results of farms in the Netherlands 
and Denmark. Tables 2.3 and 2.4 gives the results of broiler farms in the Netherlands (WUR, 2018) and Denmark, respectively.

Table 2.3 Production results of broiler farms (fast-growing broilers) in the Netherlands in the period 2014-2017

\begin{tabular}{lrrrrrr} 
& 2014 & 2015 & 2016 & 2017 & $\begin{array}{r}\text { difference } \\
\text { 2017-2014 }\end{array}$ & $\begin{array}{r}\text { difference, \% } \\
2017-2014\end{array}$ \\
live weight (gram) & 2265 & 2315 & 2388 & 2452 & 187 & 8.3 \\
\hline age (days) & 40.3 & 40.7 & 41.5 & 42.1 & 1.8 & 4.5 \\
\hline growth LW/day (gram) & 58.3 & 59.6 & 61.2 & 62.4 & 4.1 & 7.0 \\
\hline feed conversion (kg feed/kg LW) & 1.622 & 1.613 & 1.61 & 1.619 & -0.003 & -0.2 \\
\hline feed conversion at 2.25 LW & 1.618 & 1.597 & 1.576 & 1.569 & -0.050 & -3.1 \\
\hline mortality, farm level (\%) & 3.80 & 3.20 & 3.10 & 3.70 & -0.1 & -2.6 \\
\hline mortality, farm level (\%) at 40 days & 3.782 & 3.158 & 3.010 & 3.574 & -0.208 & -5.5 \\
\hline
\end{tabular}

From Table 2.3 we can conclude that between 2014 and 2017 in the Netherlands:

- Average live weight increased by 187 gram (+8.3\%).

- Feed conversion was similar in 2014 and 2017.

- Corrected feed conversion (towards $2.25 \mathrm{~kg}$ ) decreased by $0.05(-3.1 \%)$.

- Mortality decreased with $0.1 \%(-2.6 \%)$.

- Corrected mortality percentage (at 40 days) decreased by $0.2(-5.5 \%)$.

From Denmark only the 2014 and 2017 data are available. Table 2.4 gives the Danish production results.

Table 2.4 Production results of broiler farms in Denmark in 2014 and 2017

\begin{tabular}{|c|c|c|c|c|}
\hline & 2014 & 2017 & $\begin{array}{r}\text { difference } \\
2017-2014\end{array}$ & $\begin{array}{r}\text { difference, } \% \\
2017-2014\end{array}$ \\
\hline live weight (gram) & 2130 & 2130 & 0 & 0.0 \\
\hline feed conversion ( $\mathrm{kg}$ feed/kg LW) & 1.60 & 1.525 & -0.075 & -4.7 \\
\hline feed conversion (to 2.130 gram) & 1.600 & 1.525 & -0.075 & -4.7 \\
\hline mortality (\%) at 35 days & 3.426 & 3.192 & -0.234 & -6.8 \\
\hline
\end{tabular}

From Table 2.4 we can conclude that between 2014 and 2017 in Denmark:

- Average live weight didn't change.

- Feed conversion was 0.075 lower $(-4.7 \%)$.

- Mortality percentage was 0.3 lower in 2017 (-8.7\%).

- Corrected mortality percentage (at 35 days) was 0.2 lower in $2017(-6.8 \%)$.

\section{Scenarios}

Based on all the Norwegian data and the comparison with the Dutch and Danish data we come with the following assumption for the scenario if anticoccidials will no longer be used in the Netherlands (NO scenario).

Feed conversion reduction between 2014 and 2017 in the Netherlands was $3.1 \%$ and in Denmark 4.7\%. The average reduction was 3.9\%. The reduction in feed conversion in Norway between 2017 and 2014 was $1.4 \%$. The difference between Norway and Netherlands/Denmark is $(3.9 \%-1.4 \%=)$ 2.5\%.

For the Dutch situation the feed conversion without anticoccidials in the broiler feed will be $1.619 *$ $1.025=1.659(+0.04)$.

Starting point for the scenario NO is a feed conversion rate of $\mathbf{+ 0 . 0 4}$ 
Mortality relatively decreased between 2017 and 2014 in the Netherlands by $5.5 \%$ and in Denmark by $6.8 \%$.

The average reduction was 6.2\%. In Norway the mortality increased between 2014 and 2017 with $17 \%$ relatively.

The difference Norway and the Netherlands/Denmark is $23.2 \%$

For the Netherlands situation the mortality without anticoccidials in the broiler feed will be $3.7 \% *$ $1.232=4.6 \%(+0.9)$.

\section{Starting point for the scenario NO is a mortality percentage of $\mathbf{+ 0 . 9}$}

An important assumption is that the difference in technical performance between 2014 and 2017 found in Norway on the one hand and Denmark and the Netherlands on the other hand, is entirely due to the consequences of the ban on anticoccidials.

\subsection{Netherlands compared to Norway}

Feed conversion and mortality will probably increase more in the Netherlands than in the Norway case (as described in Section 2.2), due to the larger scale and higher intensity of the Dutch broiler production. To show the possible impact, a second scenario has been developed. The expert judgement of two veterinarians has been used to make the necessary estimations for this scenario.

In 2016 Norway had around 554 producers with broilers (Brantsaeter, 2018). Broiler farms are spread over most parts of Norway, except for the northern part. The main areas for agriculture are Austlandet, Rogaland and Trondelag. Broiler production is regulated by the Norwegian Concession Act. The current concession limit is 280,000 broilers per farm per year. The average number of broilers per farm per year is 115,000 (2016 situation). Based on an average 8 cycles, the average broiler farm size is approximately 15,000. Only international breeds are used in Norway and for the fast growing breeds this is mainly the Ross 308 (Brantsaeter, 2018).

Broilers are raised from day-old chicken in up to 31-33 days to a live weight of 1.7 to $2.2 \mathrm{~kg}$. Almost all broilers are raised indoor on litter/bedding material. Maximum density is $36 \mathrm{~kg}$ per $\mathrm{m}^{2}$ poultry house. In between flocks the empty period is 7 to 10 days. Thinning ( $=$ the delivery of a part of the flock to the slaughter house before complete delivery) is not practiced in Norway (Gorm Samson, 2018). Another source mentions a lower density in the field ( $34 \mathrm{~kg}$ per $\mathrm{m}^{2}$ poultry house), a minimum of 8 days of empty period and a strict cleaning programme in between flocks on all farms (Merete Forseth, 2018).

Free range and organic broiler production in Norway are very limited. Norway is self-sufficient for poultry meat.

Basic facts for the broiler sector in the Netherlands (WUR, 2018b):

- 630 broiler farms (2016).

- Family farms with on average 78,000 broilers per farm (2016).

- Self-sufficiency rate is $200 \%$.

- Imports of live broilers for slaughter in the Netherlands. 
Table 2.5 Comparison of broiler production in Norway and the Netherlands

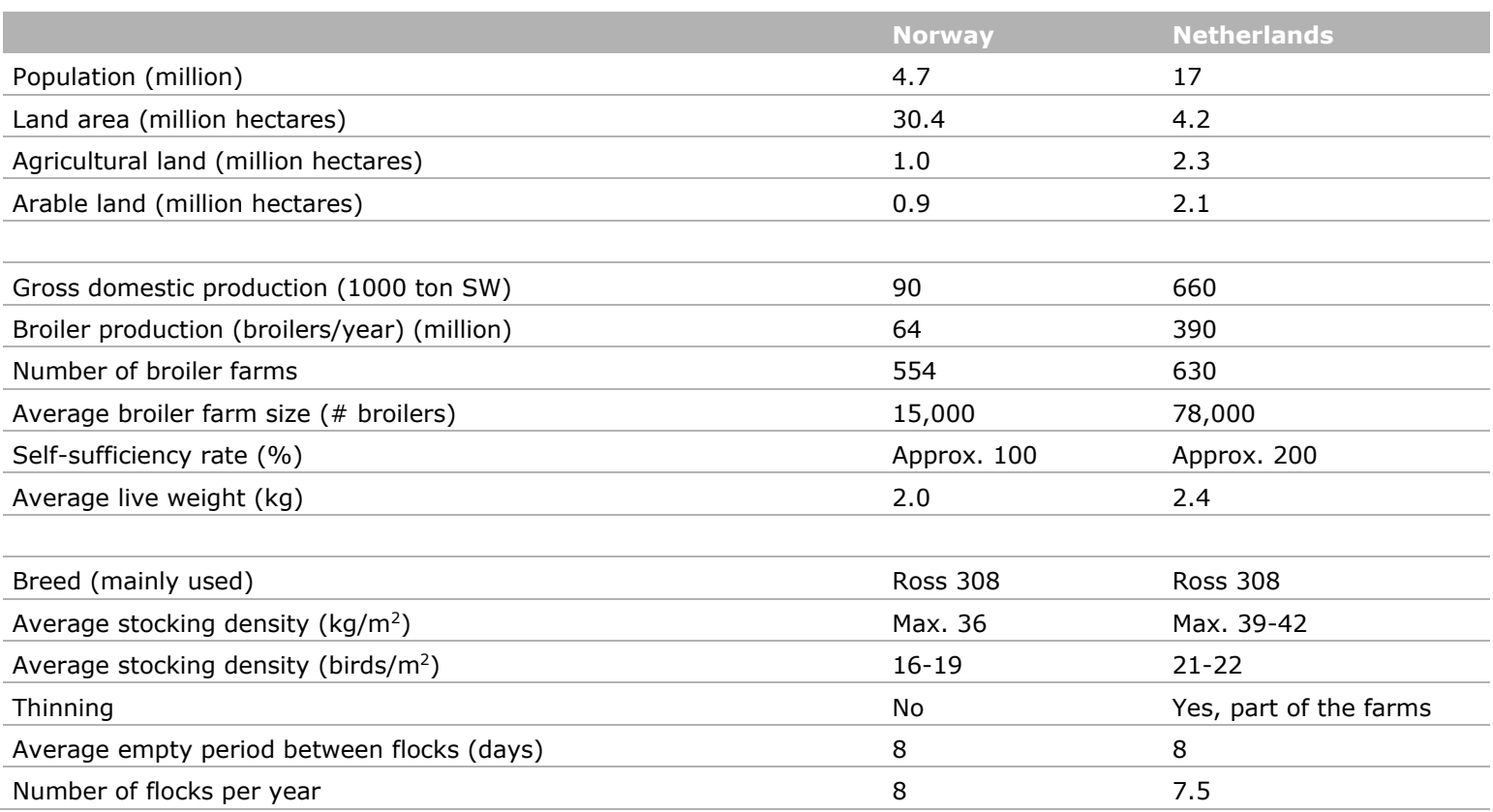

From the information in Table 2.5 it can be concluded that the Netherlands in comparison with Norway has:

- 6 to 7 times higher production of poultry meat

- more farms and much larger farms (average size 78,000 vs 15,000 broilers)

- much more broiler farms per hectare of land

- higher average live weight of broilers

- higher stocking density (in birds and live weight per $\mathrm{m}^{2}$ poultry house)

- a large part of farms apply thinning.

Stopping the routine use of anticoccidials will probably have a larger impact in the Netherlands compared to Norway. With the higher density of farms (broilers, layers and also other poultry) in the Netherlands and much more transport of live birds the infection risk is higher in the Netherlands. Due to the higher bird density and stocking density within the poultry house in combination with thinning, the larger average size of the farms and the higher average live weight in the Netherlands the production results will, after stopping the routine use of anticoccidials, probably deteriorate more than in Norway. The authors of this report discussed the current situation in the Netherlands and the differences between the Netherlands and Norway with two poultry veterinarians. Peter Wijnen is head of the poultry veterinarian office 'de Achterhoek' in the east of the Netherland and Jan Thijs Nijland is broiler specialist at the AdVee veterinarian office in Ysselsteyn in the south of the Netherlands. From these discussions it was concluded that the feed conversion and mortality will probably increase more in the Netherlands than in the Norway case (as described in Section 2.2). For this reason, an extra scenario has been calculated.

For this second scenario (scenario NL1) the estimate for the production results without anticoccidials in the broiler feed in the Netherlands the starting point is:

- feed conversion: $\mathbf{+ 0 . 0 6}$ (instead of +0.04 in the NO scenario)

- mortality percentage: $\mathbf{+ 1 . 0}$ (instead of +0.9 in the NO scenario).

\subsection{Additional costs}

In addition to the change in production results also the costs will change in a situation without anticoccidials. In this section we describe the costs of anticoccidials in the broilers feed, vaccination, probiotics and a change in feed composition. 


\section{Anticoccidials}

The costs of anticoccidials in the feed in the Netherlands are estimated to be 2.5 eurocent per broiler at farm level. The costs are estimated for the situation based on conventional broilers. In the Netherlands different anti-coccidiosis schedules are used in the field. The minimum schedule is just anticoccidials in the feed till approximately 28 days followed by finisher feed without anticoccidials. A more commonly used schedule is using anticoccidials during the whole growing period including an anticoccidials supplemented finisher feed.

\section{Vaccination}

Vaccination against coccidiosis is commonly applied by spray to young broilers (between 0-4 days of age). Spray vaccination is done on day 0 at the hatchery or at the farm. Sometimes vaccination is done via drinking water and this is done on day 3 of age at the farm. Vaccination at the farm can be carried out by the vet or by the farmer. In case the veterinarian is doing the vaccination at the farm the costs are about 0.3 eurocent per broiler ( 2 hours work @ 150 euro per hour for vaccination of 100,000 broilers). The price of 5,000 doses of the vaccine Paracox 5 is 300 euro. The price of 5,000 doses of Hipracox is 260 euro. Based on the commonly used vaccin Paracox 5 and the farmer carrying out the vaccination, the costs are 6 eurocent per broiler.

\section{Feed composition}

In a situation without anticoccidials in the feed it is very important that the broilers get a very easily digestible feed. The feed mill has to choose the right feed ingredients. This will result in a slightly higher feed price. Some feed mills in Norway give the broiler farmer more options for different feeds that the farmer can choose from depending on the disease challenge and the farm situation (Overli, 2018). In general the Norwegian feed mills made certain adaptions regarding feed ingredients and feed additives. A rough estimate is that the feed price will increase with 1 eurocent per $\mathrm{kg}$ if the use of AC will be forbidden (Overli, 2018). Another source in Norway (Forseth, 2018) mentioned small changes to the feed composition and the use of probiotics (feed additives) to improve gut health. Both Dutch veterinarians also mentioned the importance of high quality feed after a withdrawal of anticoccidials in the broiler feed. The feed should be 'easy digestible' to improve gut health and prevent digestive disorders.

\section{Additives}

Some feed mills in Norway have a good experiences with additives in the feed. Depending on the strategy of the feed mill the farmer can choose a special feed with these additives or without an additive. Norwegian companies mentioned the use of probiotics from Biomin (e.g. PoultryStar ${ }^{\circledR}$ ) and Kemin. To give an indication of the costs we calculated the additional cost of one of these products. Probiotics can be given during the first two week of the growing period. In that situation the cost will be 0.6 eurocent per broiler. In case probiotics are given during the whole growing period the costs will be around 1.5 eurocent per broiler. In this report we calculate the additional costs for adding probiotics to be 1 eurocent per broiler.

\subsection{Scenarios}

Based on all the information given in this chapter we can describe three scenarios for the situation in the Netherlands without anticoccidials in the broiler feed.

For all scenarios we calculate the additional costs of the vaccination to be 3.5 eurocent per broiler. This is the difference of the costs for vaccination ( 6 eurocent) minus the costs of anticoccidials in the feed ( 2.5 eurocent per broiler). The other consequences are:

\section{- Scenario NO} The production results in the Netherlands are similar to Norway: feed conversion is 0.04 higher and mortality percentage is 0.9 higher.

This is an optimistic scenario.

- Scenario NL1 Poorer performance than in Norway as a result of the large scale and higher intensity of broiler 
production in the Netherlands. Based on the estimate of the experts the feed conversion is 0.06 higher and the mortality percentage is 1.0 higher.

- Scenario NL2F

Additional efforts of the broiler sector in the Netherlands to reduce the impact on the production results. The result is a higher feed conversion of 0.04 and the mortality percentage is 0.5 higher. This can only be achieved with a change in the feed composition. The feed price will increase with 1 eurocent per $\mathrm{kg}$. Also probiotics are added to the broiler feed. The additional costs of probiotics are 1 eurocent per broilers. This is the most realistic scenario. 


\section{$3 \quad$ Results}

The consequences for the Dutch broiler famers in a situation without anticoccidials in the broiler feed are calculated based on three different scenarios. The scenarios are based on the information given in Chapter 2 and are in detail described in Section 2.5. Table 3.1 gives a summary of the assumptions in the basic situation (reference) and the three scenarios.

Table 3.1 Basis assumptions in the basic situation and four scenarios for Dutch broiler farms

\begin{tabular}{|c|c|c|c|c|}
\hline & Ref & NO & NL1 & NL2F \\
\hline live weight, average (gram & 2450 & 2450 & 2450 & 2450 \\
\hline feed conversion & 1.62 & 1.66 & 1.68 & 1.66 \\
\hline feed price (euro/100 kg) & 31.0 & 31.0 & 31.0 & 32.0 \\
\hline vaccination, extra costs (eurocent per broiler) & - & 3.50 & 3.50 & 3.50 \\
\hline
\end{tabular}

\subsection{Economic results}

The economic consequences are calculated with the broiler calculation tool of Wageningen Economic Research. The model and the basic assumptions are described in LEI report 2009-004 (van Horne, 2009). Indicators for the economic consequences are production costs per kg live weight and farm income. For all scenarios the economic results are calculated and presented in Table 3.2.

Table 3.2 Economic results in the basic situation and four scenarios for Dutch broiler farms

\begin{tabular}{|c|c|c|c|c|}
\hline & Ref & NO & NL1 & NL2F \\
\hline revenues per broiler housed (eurocent) & 198.1 & 196.3 & 196.0 & 197.1 \\
\hline \multicolumn{5}{|l|}{ costs per broiler housed (eurocent): } \\
\hline feed & 118.4 & 120.2 & 121.5 & 124.6 \\
\hline vaccination, extra costs & 0.0 & 3.5 & 3.5 & 3.5 \\
\hline other variable costs & 19.1 & 19.1 & 19.1 & 19.1 \\
\hline fixed costs (housing, general) & 14.9 & 14.9 & 14.9 & 14.9 \\
\hline labour & 9.0 & 9.0 & 9.0 & 9.0 \\
\hline total costs per broiler housed (eurocent) & 194.4 & 199.7 & 201.0 & 205.1 \\
\hline
\end{tabular}

An important indicator is the production costs per $\mathrm{kg}$ live weight. The revenue price of the birds is determined by the market and the broiler farmer has just a very limited influence on this market price. We calculated with an average market price of 0.84 euro per $\mathrm{kg}$ live weight. The broiler farmer has to produce at the lowest cost in order to maximise his farm income. In Table 3.2 the production costs per kg live weight are presented. The production costs are also presented in Figure 3.1. In the scenario NO the production costs increase by 3.1 eurocent $(+3.8 \%)$. In the other scenarios the production costs increase with 3.7 till 5.0 eurocent ( 4.5 till $6.1 \%$ ). The farmer has the choice either to accept poor performance results (higher feed conversion and higher mortality) or to take additional measures to reduce the impact on performance. In all scenarios the increase in costs is substantial. 


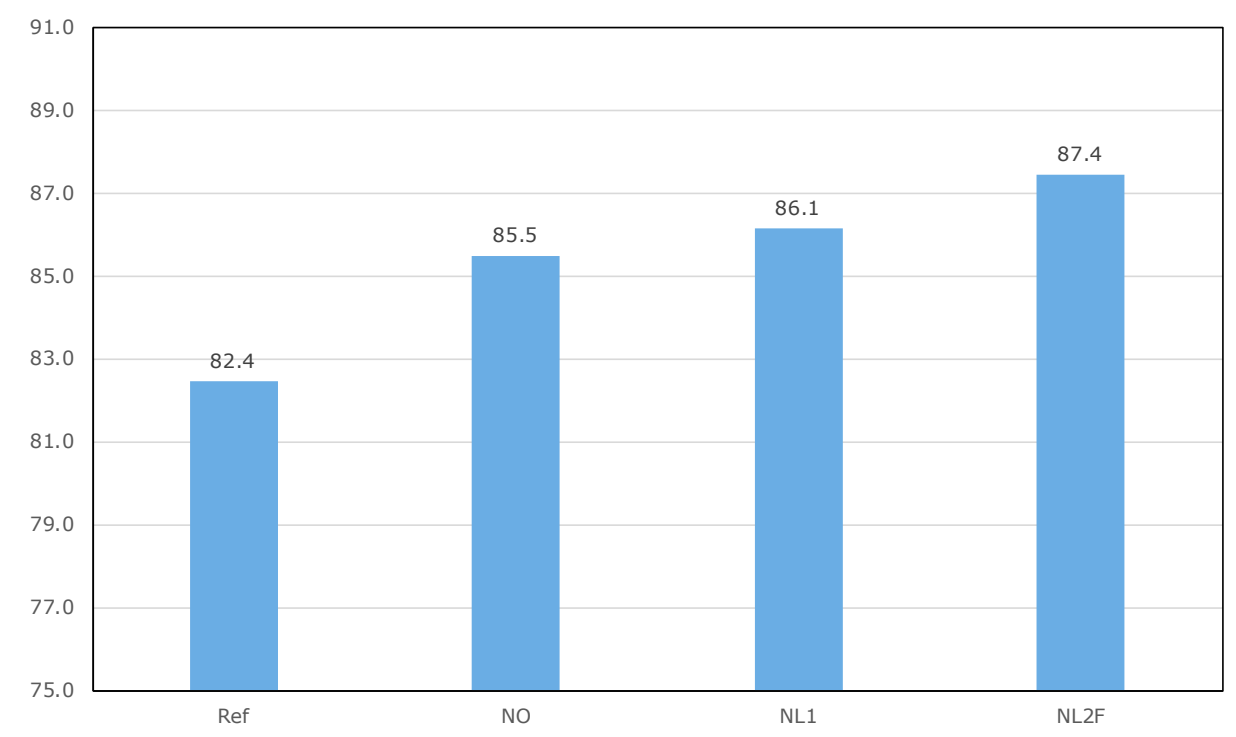

Figure 3.1 Production costs (eurocent per $\mathrm{kg}$ live weight) in the basic situation for four scenarios for Dutch broiler farms

In a situation with no anticoccidials in the broiler feed only in the Netherlands, and no EU wide ban on the use of anticoccidials, no impact on the revenue price is to be expected. The Dutch companies are operating in an international market and more than half of the production of Dutch slaughterhouses in exported. Based on a fixed revenue price per kg live weight we calculated the revenues per bird housed. The first line in Table 3.1 gives the revenues. As a result of a higher mortality rate, the revenues per bird housed are slightly lower in all the scenarios. The farm income can be calculated by taking the difference of the revenues of all the costs, except the costs for labour. Starting point is a farm with 90,000 broilers and the farmer doing the work in the farm. The calculated farm income is the gross income for the farmer. All other costs for housing (depreciation) and interest on the invested capital are taken into account as fixed costs. Figure 3.2 gives the farm income for a farm with 90,000 broilers in the basic situation and the three scenarios.

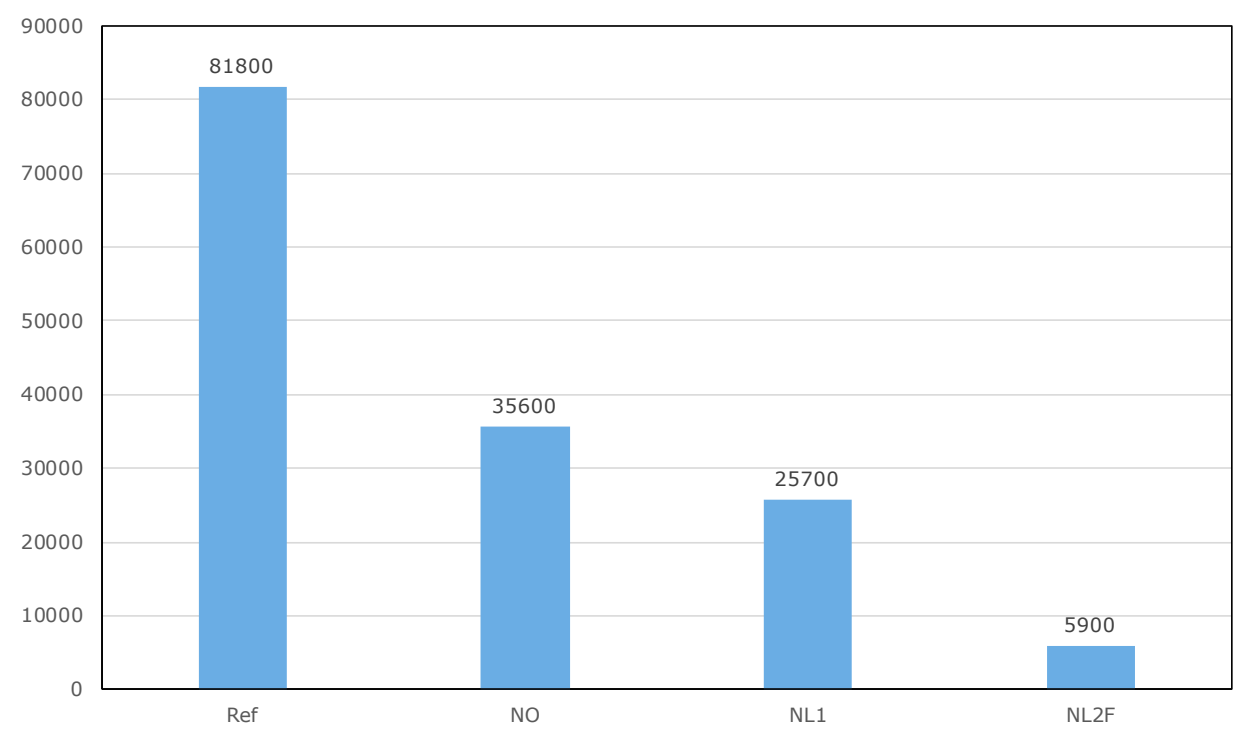

Figure 3.2 Farm income (euros per year) for Dutch broiler farms in the basic situation and three scenarios 
In the reference situation the farm income is 81,800 euro, which is the average income of broiler farms during the last six years 2012-2017 (WUR, 2018c). The income of broiler farms is calculated every year by Wageningen Economic Research. In the scenario NO farm income is reduced to 35,600 euro $(-56 \%)$. In the two NL scenarios income is further reduced to 25,700 (NL1 scenario) or even 5,900 euro (for the NL2F scenario). In all scenarios the revenue price stays the same and production costs are increased due to poor performance and additional costs for vaccination, improved feed or probiotics.

In a situation with higher production costs and no higher revenue prices a part of the Dutch farmers will stop farming. This will have direct consequences for the chain partners such as hatcheries, feed mills and slaughterhouses. The broiler supply chain in the Netherlands employs 16,000 workers. A part of these workers will be unemployed in the new situation.

\subsection{Environmental impact}

Poultry production has an impact on the environment. The impact can be quantified by applying the Life Cycle Assessment (LCA methodology). LCA is a method for an integrated analysis of environmental impact along the life cycle of a product. The LCA method used for poultry production is described by Vellinga et al. (2013) and Leinonen et al. (2012). The impact on the environment has several categories such as global warming potential (GWP), eutrophication potential (EP), acidification potential (AP), primary energy input and land use. In this report we focus on the main indicator global warming potential which has a universal impact.

Poultry manure is the source of direct gaseous emissions of ammonia $\left(\mathrm{NH}_{3}\right)$ and nitrous oxide $\left(\mathrm{N}_{2} \mathrm{O}\right)$ that occur during housing of the animals and storage. Also during arable production producing the main feed ingredients of broiler feed greenhouse gases are produced. The total impact on the environment is calculated as total $\mathrm{CO}_{2}$ equivalent emission (also called the carbon foot print). It is the total of the emission of $\mathrm{CO}_{2}, \mathrm{NH}_{3}$ and $\mathrm{N}_{2} \mathrm{O}$. For broiler farming the total $\mathrm{CO}_{2}$ equivalent emission is expressed per $\mathrm{kg}$ of live weight.

The Paris Agreement is an agreement with the United Nations Framework Convention on Climate Change dealing with greenhouse gas emission. The Paris Agreement long-term goal is to keep the increase in global average temperature below 2 degree Celsius. Under the Paris Agreement, each country will report on the contribution that it undertakes to mitigate global warming. The Netherlands Parliament passed a bill in June 2018 mandating that greenhouse gas emission level will be reduced in order to exceed the Paris Agreement goals. The Dutch coalition agreement states that the $\mathrm{CO}_{2}$ emission in 2030 will be reduced by 49\% compared to 1990 .

Especially feed intake has a large impact on the carbon foot print. The production of crops, transport of feed ingredients, feed processing and transport of feed to the farms gives directs emissions. For this reason we focus on the impact of a higher feed conversion on the carbon foot print. We compare three situations:

- Conventional Dutch broiler housing with use of anticoccidials in broiler feed

- Dutch broiler housing without use of anticoccidials and a feed conversion increase of 0.04 (scenario NO).

- Dutch broiler housing without use of anticoccidials, and a feed conversion increase of 0.06 (scenario NL).

The carbon foot print of the conventional Dutch broiler farm was calculated by Blonk in a report of ABN AMRO bank (Berntsen, 2018). Based on this reference situation the carbon foot print was calculated for both situations with a higher feed conversion. Figure 3.3 gives the results. 


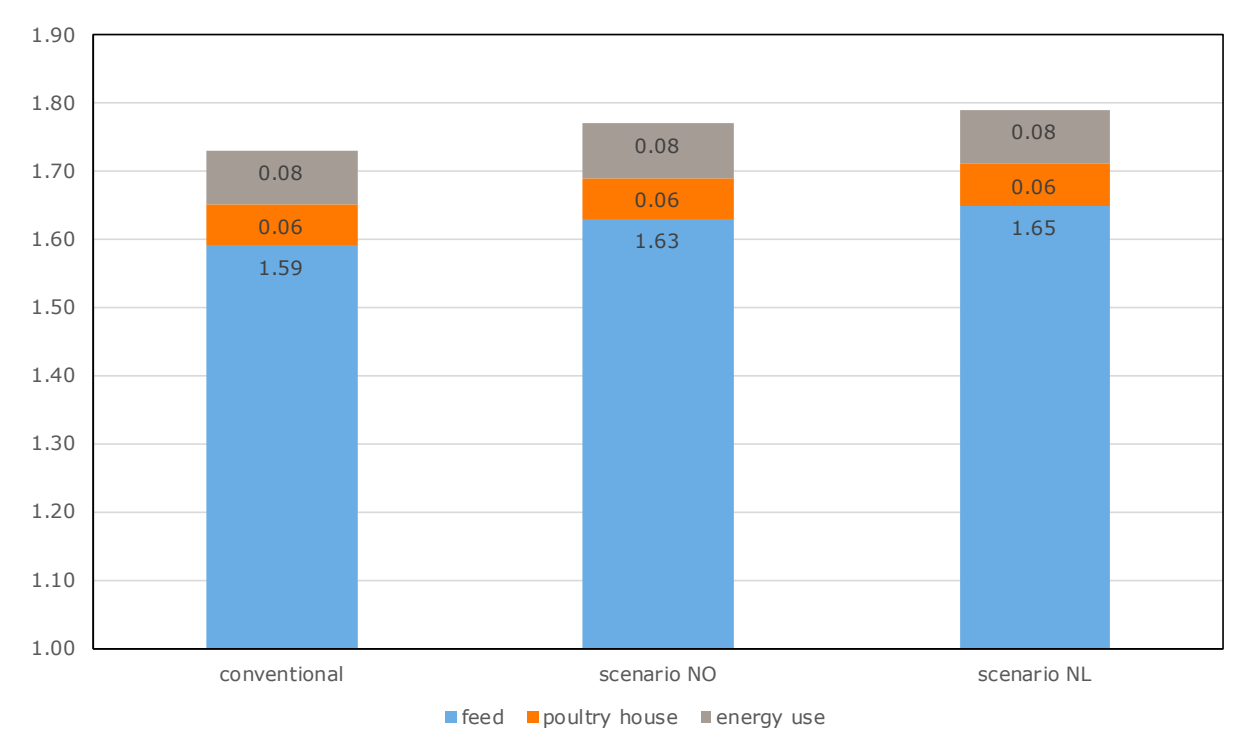

Figure 3.3 Carbon foot print (in $\mathrm{kg} \mathrm{CO}_{2}$ equivalent per $\mathrm{kg}$ live weight broiler) in the basic situation and two scenarios with a higher feed conversion

Source: Blonk, 2018. Adapted by Wageningen University \& Research.

Figure 3.3 clearly illustrates the impact of an increased feed conversion (component feed) on the total $\mathrm{CO}_{2}$ emission. The total carbon foot print did increase from 1.73 (basic situation) to $1.77 \mathrm{CO}_{2}$ equivalents $(+2.3 \%)$ for scenario $\mathrm{NO}$ and $1.79(+3.4 \%)$ for scenario NL1.

\subsection{Other aspects}

\section{Footpad score}

An important indicator for animal welfare is the footpad score. The average footpad score on the Norwegian farms in 2014, as presented in Table 2.1, was 18. In the following years 2015, 2016 and 2017 the average score was 12, 11 and 13. Compared with the Netherlands, these scores are very low. Average footpad score in the Netherlands in 2014 and 2017 was 63 and 37 points, respectively. Looking at the Norwegian data it can't be concluded that stopping with the routine use of anticoccidials in the feed had no influence on the footpad score. One Norwegian specialist (Forseth, 2018) mentioned that footpad lesions increased 'quite a bit' after stopping the use of anticoccidials, but if we look at the collected data, this could not be confirmed. She is suggesting that the litter quality has deteriorated.

Wider variation in results/mortality

Some Norwegian experts report a wider variation in production results after stopping the routine use of in-feed anticoccidials (e.g. Hanna Overli, 2018). This is especially valid for the mortality rate. The results in Table 2.1 show an increase in mortality percentage at farm level from 2.64 in 2014 to 3.18 in 2017. To further analyse the mortality percentage we made a graph of the mortality rate in 2014 and 2017 giving the $25 \%$ quartile, the average and the $75 \%$ quartile. Figure 3.4 gives the results. 


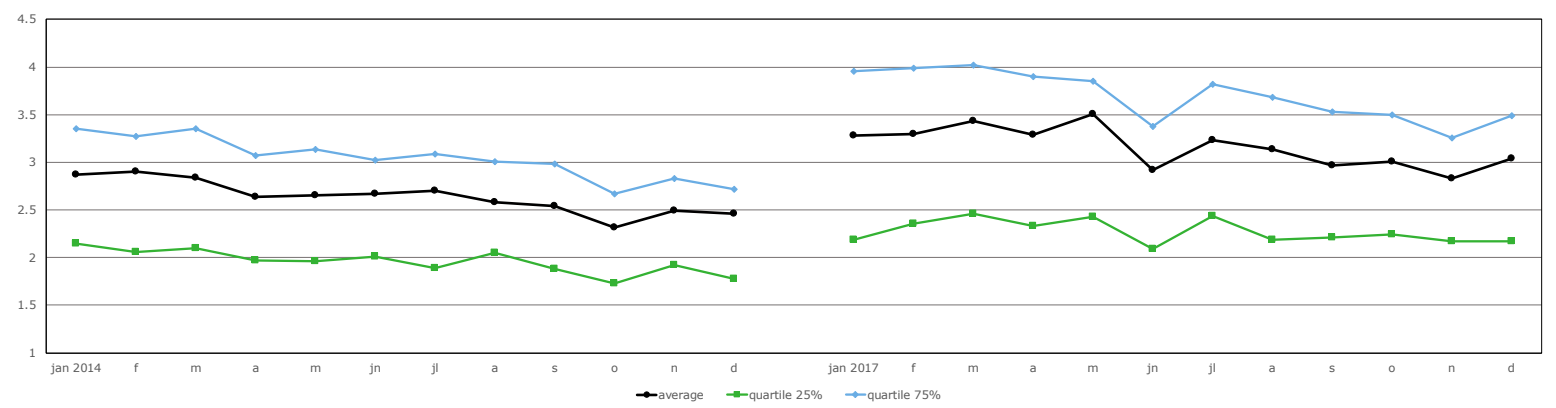

Figure 3.4 Variation of mortality percentage between flocks in 2014 and 2017

Figure 3.4 illustrates that the difference between the 25 and 75 quartile is higher in 2017 compared to 2014. In 2014 the average mortality in the 25 and 75 quartile was 1.96 and 3.04. The difference is 1.08. In 2017 the average mortality in the 25 and 75 quartile was 2.27 and 3.70 . The difference is 1.43. This difference is $32 \%$ higher than in 2014 . These data indicate that there is a wider variation in between flocks after stopping the routine use of anticoccidials.

Also the Dutch poultry vets mentioned that a larger variation in mortality can be expected after not using anticoccidials in broiler feed. A more unpredictable flock result makes planning by the farmer and slaughterhouse more complicated. A proper planning based on actual numbers makes the production chain more efficient.

\section{Rejects/liver condemnation}

Some Norwegian experts report an increase in rejects and liver condemnation. Forseth (2018) states especially in the first few months an almost double number of rejects. due to liver condemnation. Later this reduced to a lower level, but still above the level in the period with use of anticoccidials in the feed. She links the rejects in the slaughterhouse to 'liver lesions' (cholangiohepatitis). Also Edvardsen (2018) states that liver condemnations have gone up after not standard using of anticoccidials.

Nortura also registered the percentage of rejects is registered. These data could give an indication of the health status of the broilers. Table 3.3 gives the data for the years 2014, 2015, 2016 and 2017. The Nortura data show a steady increase in rejects from 2014 towards 2017.

Table 3.3 Percentage of rejects in the slaughterhouse (Nortura data)

\begin{tabular}{lrrrr} 
& 2014 & 2015 & 2015 & 2016 \\
average & 1.20 & 1.40 & 1.54 & 0.94 \\
\hline Quartile, $25 \%$ & 0.75 & 0.82 & 1.68 \\
\hline Median, 50\% & 1.06 & 1.18 & 1.04 \\
\hline Quartile, $75 \%$ & 1.48 & 1.77 & 1.89 & 2.09 \\
\hline
\end{tabular}

Also the Dutch veterinarians expect a higher percentage of rejects and liver condemnations in a situation without anticoccidials in the broiler feed. It is difficult to estimate the economic value of liver condemnations. It depends on slaughter house if the whole carcass is condemned after finding liver lesions.

\section{Use of antibiotics}

Norway has a very strict policy on the use of antibiotics. Only in a very exceptional situation antibiotics are used for broilers. Thorbjorn (2018) states that the use of antibiotics has not increased after using the anticoccidials. However, there are no official data available on the use of antibiotics in Norway in recent years. Stopping the routine use of anticoccidials does lead to increased risk of incidence of clinical necrotic enteritis with higher mortality rates (as the Norwegian data show). The Dutch veterinarians state that any increase in mortality in the Netherlands in a situation without 
anticoccidials would not be acceptable for farmer and veterinarian. In the Netherlands veterinarians and farmers will choose to treat with antibiotics to control mortality and also to preserve animal health and animal welfare.

In the Netherlands broiler farms have to work according EU Directive 2007/43/EC, giving minimum rules for the protection of chickens for meat production. Part of this directive is setting maximum stocking densities. Farmers can work with a higher stocking density if mortality rate is under a certain target value. For this reason Dutch farmers prefer very low mortality rates. Farms with a higher mortality rate are forced to reduce the stocking density which directly leads to higher production costs and loss of income. All these above mentioned factors will lead to an increase in the use of antibiotics in the Netherlands, in a situation without routine use of anticoccidials. 


\section{$4 \quad$ Conclusions}

- The results of broilers farms of a large Norwegian slaughterhouse show that after stopping the routine use of anticoccidials in the feed the production results deteriorated. Comparing the situation of 2014 (before) with 2017 (after) gave a higher mortality and a poorer feed conversion in 2017.

- Normally broiler production results improve year by year as a results of genetic improvements. To show the improvement between 2014 and 2017 the production results of the Netherlands and Denmark were compared to the data of Norway. Based on this comparison it was concluded that the impact of stopping the routine use on anticoccidials in the broiler feed in Norway gave a higher feed conversion of 0.04 point and a higher mortality percentage of 0.9 .

- In the Netherlands the structure of the broiler sector is different from Norway. There are more broilers farms in a small region, the average farm size is much larger, the density on the farm is higher and farmers grow the birds to a higher live weight. All these factors will have an impact on the production results after stopping the routine use of anticoccidials in the broiler feed in the Netherlands. The WUR researchers discussed the consequences with two poultry veterinarians and it was concluded that a higher feed conversion of 0.06 and a higher mortality percentage of 1 can be expected for the Netherlands.

- To show the economic consequences for the Dutch broilers farmers in a situation without anticoccidials in the broiler feed three scenarios were described. In all scenarios the additional costs of vaccination instead of anticoccidials in the feed are 2.5 eurocent. In scenario NO the feed conversion is 0.04 higher and mortality percentage is 0.9 higher. In scenario NL1 the feed conversion is 0.06 higher and mortality is 1.0 higher. In Scenario NL2F feed conversion is 0.04 higher, mortality percentage is 0.5 higher combined with an additional change in feed composition (higher feed price of 0.01 euro per $\mathrm{kg}$ ) and adding probiotica ( 0.01 euro per broiler).

- Total production costs are 82.4 eurocent per $\mathrm{kg}$ live weight in the reference situation. In scenario NO the costs are $85.5(+3.8 \%)$, scenario NL1 86.1 ( $+4.5 \%)$ and scenario NL2F $87.4(+6.1 \%)$. Total farm income of a Dutch farm in the reference situation is 81,800 euro. In scenario NO the income is reduced to 35,600 euro, in scenario NL1 25,700 euro en in scenario NL2F 5,900 euro.

- A higher feed conversion also has an environmental impact. The extra production of crops, transport of feed ingredients, feed processing and transport gives direct emissions. With a higher feed conversion of 0.04 and 0.06 the total carbon foot print at farm level increased from 1.73 in the reference situation to 1.77 and 1.79 respectively. This is increase of 2.3 and $3.4 \%$.

- Stopping with the routine use of anticoccidials will result in a wider variation in results. This is especially valid for mortality rate. This makes planning by the farmers and slaughterhouse more complicated and makes the production chain less efficient. In a situation without anticoccidials in the feed more rejects and liver condemnation can be expected.

- Stopping the routine use of anticoccidials in the Netherlands situation will lead to an increased use of antibiotics. First, because an increased risk of incidence of clinical necrotic enteritis will give a higher mortality. To prevent an increase in mortality animals will be treated with antibiotics. In the Netherlands farmers, veterinarians and the government don't want an increased mortality. Veterinarians will choose to preserve animal health and animal welfare. Second, an increase in mortality could force farmers to reduce the stocking density, due to EU legislation, and this will have a direct negative impact on farm income.

- In a situation with higher production costs and no higher revenue prices a part of the Dutch farmers will stop farming. This will have direct consequences for the chain partners such as hatcheries, feed mills and slaughterhouses. The broiler supply chain in the Netherlands employs 16,000 workers. A part of these workers will be unemployed in the new situation. 


\section{References and websites}

Brantsaeter, M., 2018. Managing director of Norsk Fjorfelag. Norwegian Poultry Production. Powerpoint on the situation in the Norwegian poultry sector 2017. June 2018.

Berg, L., 1998. Foot pad scoring in Sweden.

Berntsen, P. Ruimte voor kip. Concept als standaard. ABNAMRO, Amsterdam. 18 juli 2018. www.abnamro.nl

Edvardsen, D. Norges For. Personal communication, 18 January 2018.

Forseth, M., 2018. Norsk-kylling. Personal communication. Mail 12 feb 2018.

Horne, P. van. Productiekosten van kuikenvlees. Een internationale vergelijking. LEI Wageningen UR report 2009-004. Den Haag. Maart 2009.

Leinonen et al., 2012. Predicting the environmental impacts of chicken systems in the United Kingdom through a life cylce assessment: Broiler production systems. New Castle University. Poultry Science 91:8-25.

Nortura, 2018. Flocks results. htpps://medlem.nortura.no/fjorfe

Overli, Hanna 2018. Felleskjopet. Productmanager Poultry feed. Mail 2 august 2018

Thorbjorn, R., 2018. ANIMALIA, Norwegian Meat and Poultry Research Centre. Oslo. Mail 21 June.

Samson, G., 2018. Nortura. Personal communication, May 25, 2018

Vellinga, Th. et al. Methodology used in FeedPrint: a tool to quantifying greenhouse gas emissions of feed production and utilization. Wageningen Livestock Research. Report 674. Wageningen, March 2013.

WUR, 2018. Wageningen Economic Research. Average production results Dutch broiler farms.

WUR, 2018b. Wageningen Economic Research. Broiler production chain. www.agrimatie.nl

WUR, 2018c. Wageningen Economic Research. Farm income broiler farms. www.agrimatie.nl 


\section{Appendix 1 Nortura slaughter control data: feed conversion 2014 and 2017}

Data 2014
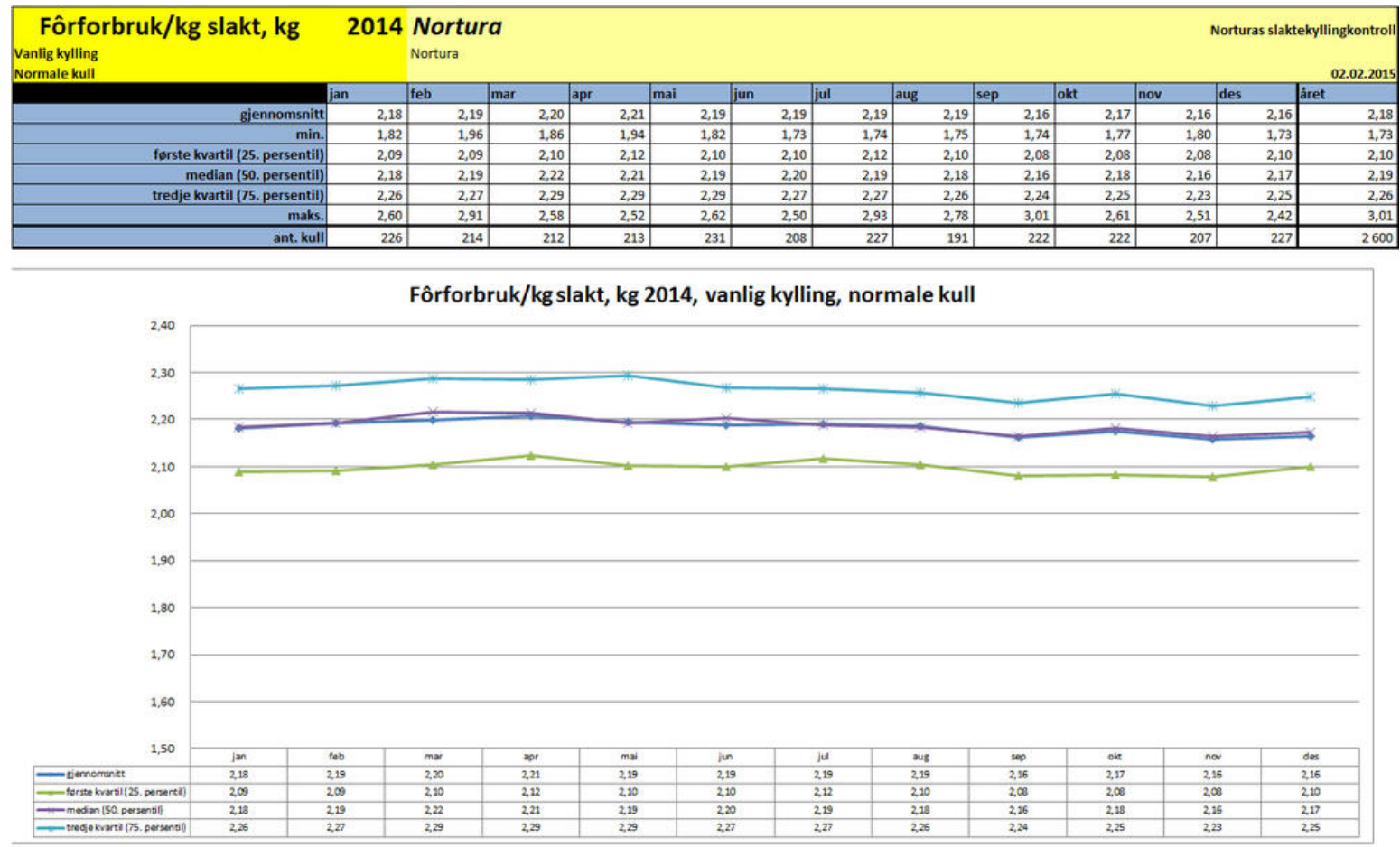

Data 2017

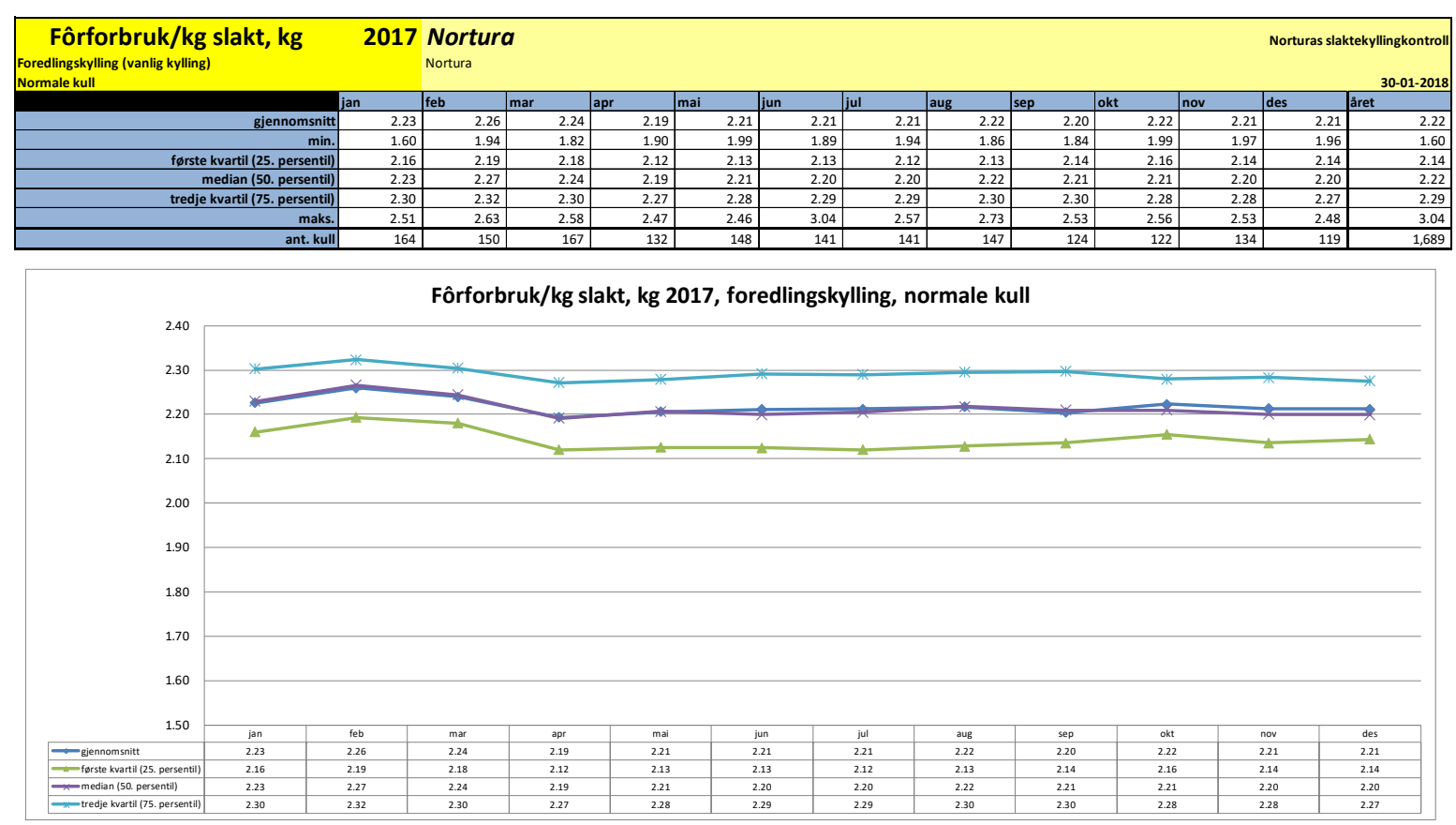




\section{Appendix 2 Nortura slaughter control data: mortality percentage data 2014 and 2017}

Data 2014
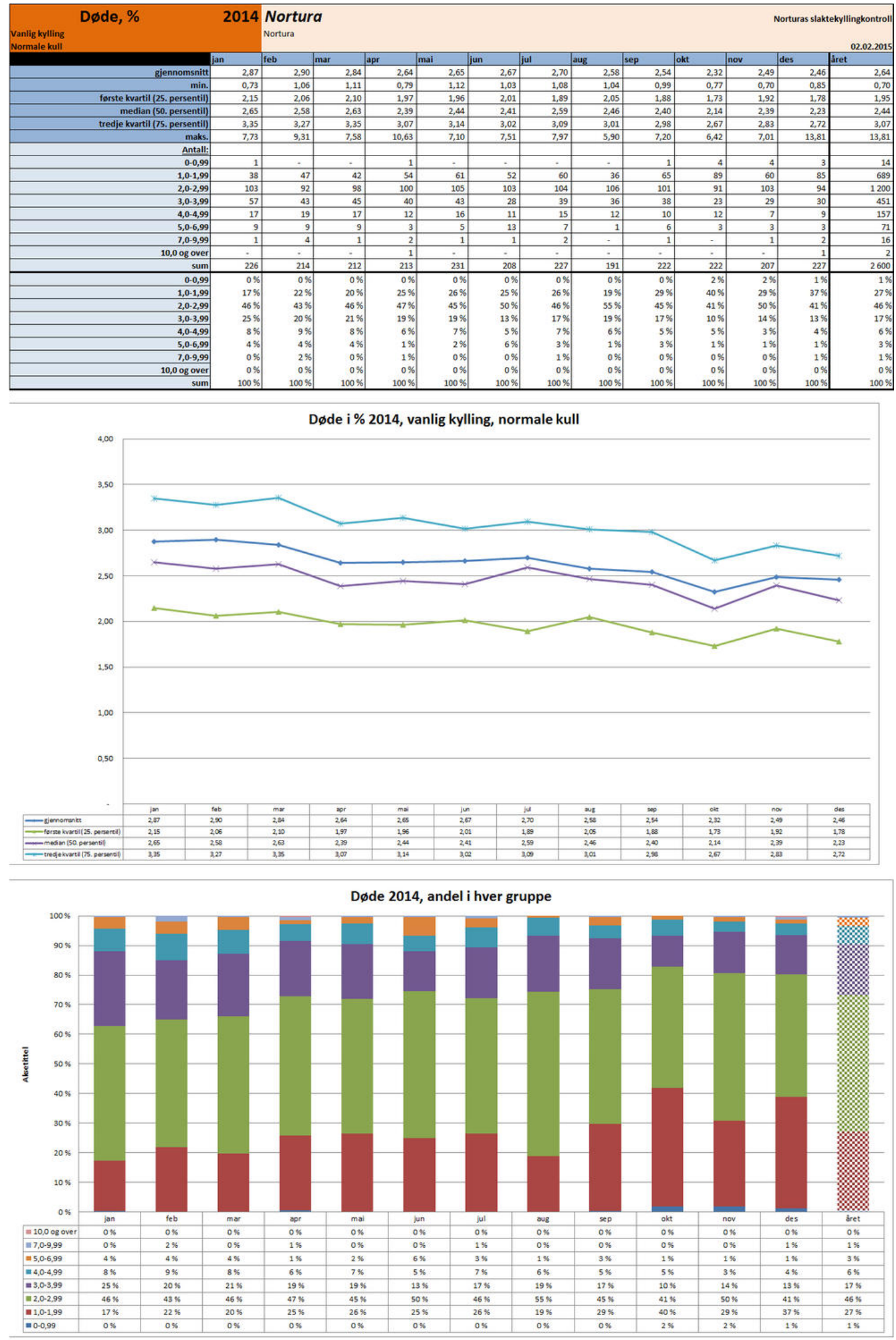

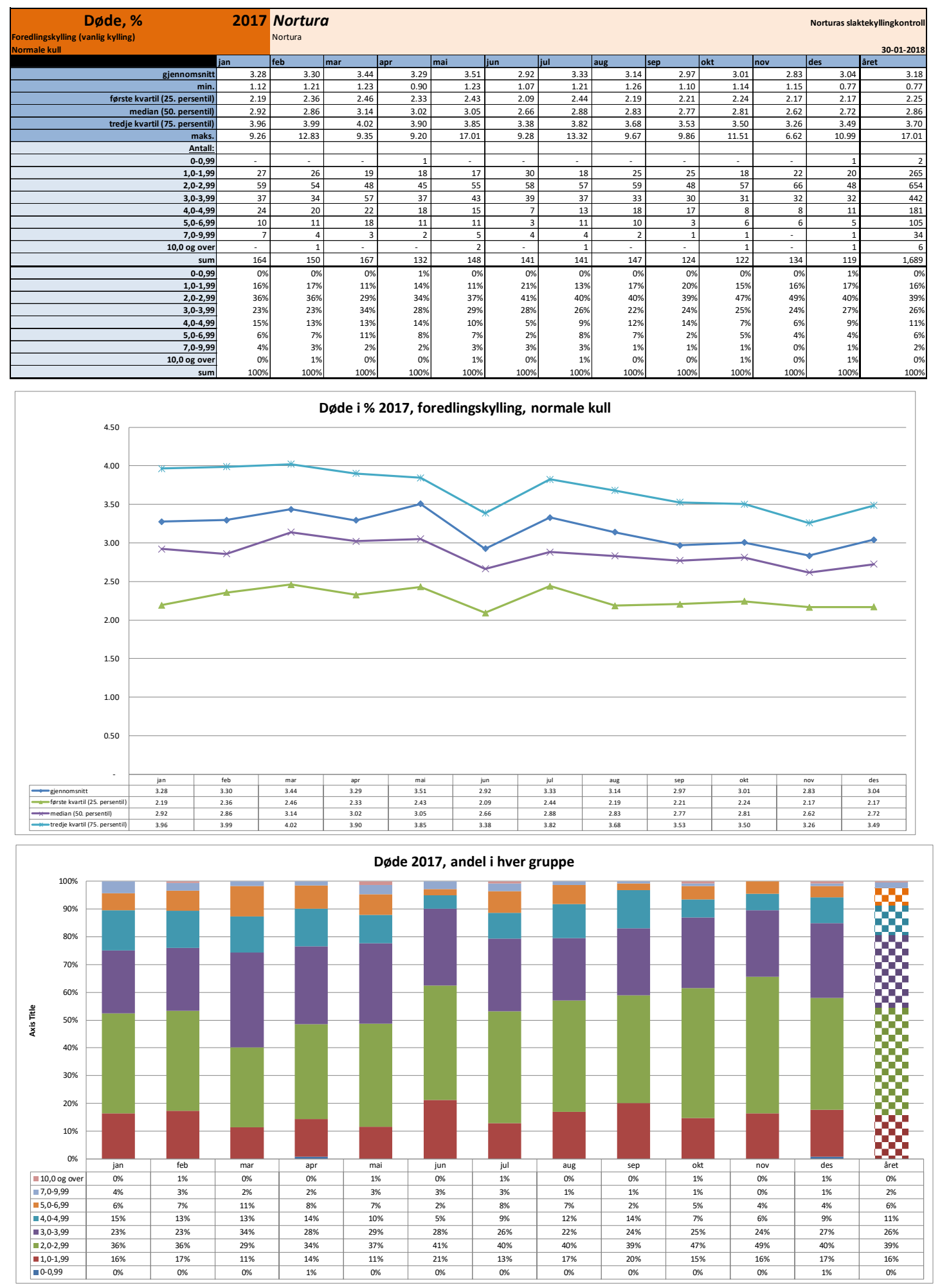
Wageningen Economic Research P.O. Box 29703

2502 LS The Hague

The Netherlands

$\mathrm{T}+31(0) 703358330$

E communications.ssg@wur.nl

www.wur.eu/economic-research

Wageningen Economic Research REPORT

2019-004
The mission of Wageningen University \& Research is "To explore the potential of nature to improve the quality of life". Under the banner Wageningen University \& Research, Wageningen University and the specialised research institutes of the Wageningen Research Foundation have joined forces in contributing to finding solutions to important questions in the domain of healthy food and living environment. With its roughly 30 branches, 5,000 employees and 10,000 students, Wageningen University \& Research is one of the leading organisations in its domain. The unique Wageningen approach lies in its integrated approach to issues and the collaboration between different disciplines.

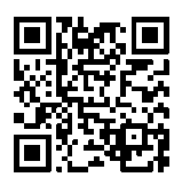





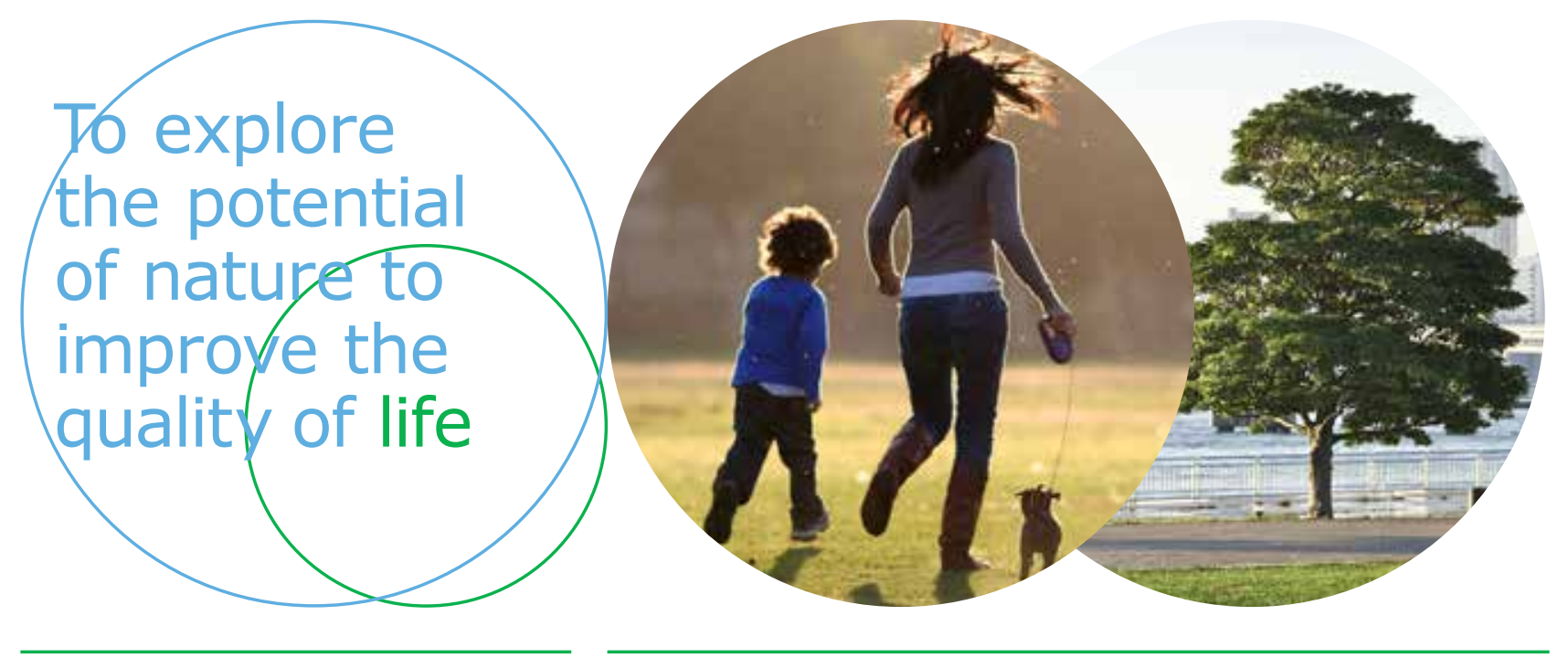

Wageningen Economic Research Postbus 29703

2502 LS Den Haag

E communications.ssg@wur.nl

$\mathrm{T}+31(0) 703358330$

www.wur.nl/economic-research

Report 2019-004

ISBN 978-94-6343-585-7
De missie van Wageningen University \& Research is 'To explore the potential of nature to improve the quality of life'. Binnen Wageningen University \& Research bundelen Wageningen University en gespecialiseerde onderzoeksinstituten van Stichting Wageningen Research hun krachten om bij te dragen aan de oplossing van belangrijke vragen in het domein van gezonde voeding en leefomgeving. Met ongeveer 30 vestigingen, 5.000 medewerkers en 10.000 studenten behoort Wageningen University \& Research wereldwijd tot de aansprekende kennisinstellingen binnen haar domein. De integrale benadering van de vraagstukken en de samenwerking tussen verschillende disciplines vormen het hart van de unieke Wageningen aanpak. 